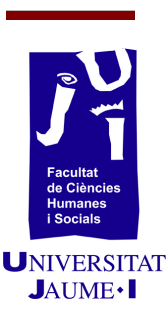

\title{
La violencia sexual en la mitología griega y su presencia en el rapto de Europa
}

Noelia Alemany Mesas al259464@uji.es 


\section{Resumen}

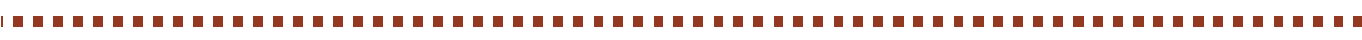

La violencia ejercida sobre el sexo femenino ha constituido un aspecto bastante notable en la sociedad desde tiempos antiguos. La violencia en general y la sexual en particular, se habían convertido en un modo más de expresar el dominio que el hombre poseía sobre la mujer. Con el tiempo, esta pasó a reflejar la esencia del patriarcado, un sistema que trataba constantemente de fomentar la autoridad y la potestad del sexo masculino, quien pretendía hacerse escuchar siempre por encima de los demás, especialmente por encima de las mujeres, relegándolas a un segundo plano. La mitología griega no solo refleja en sus contenidos el sexismo imperante en la sociedad antigua, sino que a través de los mitos se contribuía a la naturalización, legitimación y reproducción del patriarcado. Es así como numerosos aspectos relacionados con la violencia aparecen en los mitos cogidos de la mano de alguna figura femenina, que es la quien sufre siempre las consecuencias.

A través del rapto de Europa y los principales autores clásicos que aluden a este relato mitológico en sus escritos, se reflexiona en este trabajo el modo en que se ejerce la violencia sobre la protagonista. El objetivo es mostrar que un mismo hecho violento se puede representar e interpretar de distintas formas según la persona y el punto de vista que adopte ante una misma situación. Esto a su vez incluye, de forma automática, un estudio sobre el concepto central que envuelve su figura: el rapto mitológico, pues es el elemento que une gran parte de los relatos griegos donde el factor predominante es la violencia de carácter sexual que se ejerce sobre una figura del sexo femenino.

Palabras clave: Europa, rapto, violencia sexual, víctima, sexo femenino, mitología.

\section{Introducción}

El estudio propuesto es el inicio de un proyecto de investigación insertado en la categoría del género. Partiendo del rapto de Europa se pretenden comprobar varias cosas, la más relevante de ellas es la repercusión que alcanzó la violencia sexual en la mitología griega. Acorde con las características del trabajo, resultaría inviable analizar todos los autores clásicos que dedican unas líneas a este rapto. Así pues, se ha decidido centrar la investigación en el estudio de dos autores concretos -Mosco de Siracusa y Horacio-, para observar mejorar cómo se interpreta la violencia sexual sufrida por Europa durante el rapto, ya que son dos de los autores que más importancia le dan a su figura, mientras que otros prefieren hablar mejor del 
raptor o cualquier otro aspecto alejado de la protagonista, normalmente vinculado al secuestrador, en este caso Zeus.

Para estudiar la violencia sexual hallada en los pasajes de Mosco de Siracusa y Horacio sobre el rapto de Europa, es importante tratar algunos aspectos teóricos previamente, ya que son ellos los que van a aportar información necesaria a la hora de su análisis. En primer lugar, se va a enmarcar el tema reflexionando sobre el modelo de mujer "víctima» expuesto en los mitos y la relación que mantiene con la violencia. Dentro de este punto genérico, se va a profundizar en las razones que llevan a focalizar la violencia en el sexo femenino, aludiendo sobre todo al carácter desigual que se da entre ambos sexos. A continuación se define el concepto de violencia y se divide en tres subcategorías distintas para facilitar su estudio y poder observar, con mayor precisión, el tipo de subcategoría que le corresponde al rapto de Europa -en este caso el de violencia sexual. Por otra parte, resulta también interesante abordar un pequeño estudio sobre la narración de este rapto, que llevará a distinguir los tipos de interpretaciones que se dan sobre la violencia sexual según la forma de entender esta clase de episodios mitológicos.

\section{Objetivos}

Básicamente son dos los objetivos principales que se pretenden alcanzar a través del presente artículo. El primero que se plantea consiste en estudiar la correspondencia que adquiere el papel femenino de la mujer en los mitos con el contexto histórico-social en el que estos convivieron, analizando para ello la violencia que se ejerce en ambos sobre el sexo femenino. Parece evidente que la imagen que se percibe de ellas en la mayoría de los mitos se ve bastante influenciada, en este sentido, con la realidad del momento en el que les tocó vivir. Es más, se podría afirmar ya de antemano, que la idea que se tiene sobre su figura recae directamente en el pensamiento que la sociedad tenía sobre las mujeres. De este modo quedaría expuesto y justificado el promotor o causante principal de este hecho: el propio contexto histórico-social. Es él, con su sistema patriarcal, el que configura una mitología de carácter misógino donde la violencia ejercida sobre la mujer queda justificada.

El segundo de los objetivos va dirigido hacia un tipo concreto de violencia: la violencia sexual. A través de un ejemplo tan claro como es el rapto de Europa, se pretende estudiar el modo en que se representa la violencia sexual en la mitología griega. Gracias a este análisis se observará que un mismo hecho violento se puede representar e interpretar de distintas formas según la persona y el punto de vista que estos adopten ante una misma situación violenta. 
Para llevar a cabo este estudio se requiere el uso de obras relacionadas con la Antigua Grecia, la mitología y el género, ya que son los tres elementos fundamentales sobre los cuales se compone el artículo. El libro de Maria Dolors Molas Font y otros - La violencia de género en la antigüedad-, el artículo de la profesora Alicia Esteban Santos - «Mujeres terribles (Heroínas de la mitología griega)»- o la conferencia impartida en el $X$ Seminario de Arqueología Clásica por Assela Alamillo -«El rapto en la mitología clásica»- son vitales para desarrollar el tema. Tampoco hay que olvidar las fuentes clásicas de las cuales parte el análisis alusivo a la violencia sexual que se muestra en el rapto de Europa.

El interés personal por la mitología y el seguimiento de la anterior línea de investigación relacionada con el rapto de Europa en el ámbito artístico son los dos aspectos que han llevado a la configuración de este artículo. Un artículo centrado en los estudios de género, pues son la herramienta más adecuada para hablar de la condición femenina. Además, son ellos los que ayudan a elaborar interpretaciones históricas y filosóficas al respecto como las que se pretenden alcanzar en el presente estudio.

\section{Resultados}

En primer lugar, se estudia el prototipo general de mujer «víctima» en la mitología griega y su relación con la violencia, aportando información necesaria sobre ambos para poder entender mejor el análisis posterior realizado con base en la figura de Europa y el rapto que protagonizó junto a Zeus, el dios supremo.

\section{Mujer como «víctima» y su relación con la violencia}

Existen muchos tipos de clasificaciones en cuanto a la imagen femenina mitológica se refiere. Son muchos los caracteres que esta adopta en las distintas narraciones, al igual que las funciones que ejerce en cada una de ellas. Aun así la mayoría de estos personajes comparten un rasgo en común, y es que son "víctimas» de forma directa o indirecta de la brutalidad del varón (Esteban, 2005: 66), lo cual se debe principalmente a la caracterización que los autores clásicos -todos ellos varones- hicieron en su momento sobre las mujeres, ya que les proporcionaron únicamente aquellos rasgos que creían específicos en el género femenino. Por tanto, la visión que los hombres tenían sobre las mujeres en la sociedad antigua influyó considerablemente en la elaboración de dichos personajes, de modo que se podría decir que ese rasgo que las une no es más que la consecuencia directa del sistema patriarcal establecido en la Antigua 
Grecia. Un sistema «basado en el prejuicio sexista de la inferioridad natural del sexo femenino que da lugar a relaciones sociales asimétricas y jerárquicas entre hombres y mujeres" (Molas, 2006: 34-35). $Y$ es que tales relaciones suelen apoyarse en los mitos de prácticas violentas, bien sean físicas, sexuales o puramente simbólicas, de forma que consiguen fortalecer, más allá del panorama social, la supremacía del varón sobre la mujer.

Una de las múltiples posibilidades que tenía el ser humano de expresar la desigualdad entre hombres y mujeres en la mitología griega, era aplicando la violencia sobre el sexo considerado inferior, es decir, el femenino. Se pretendía conseguir así degradar la figura femenina para poder engrandecer más fácilmente la masculina, y demostrar una vez más quien tenía la potestad y el control sobre todo. Solían utilizar la excusa de que los hombres y las mujeres no somos iguales; que ellos disponen de unas capacidades que nosotras no poseemos y que son vitales para el funcionamiento y la estabilidad de una sociedad. Sin embargo, el hecho de "ser diferentes no significa[ba] ser desiguales» (Ruíz, 2004: 8). En realidad las mujeres somos igual de capaces que los hombres y nuestras habilidades tienen la misma validez que las suyas, por tanto la desigualdad entre sexos debería ser algo impensable. Por el contrario, la sociedad veía normal ese trato al no haber conocido otra cosa. Incluso algunos investigadores en la actualidad siguen aceptando la realidad expuesta en los mitos, defendiendo las numerosas violaciones acontecidas en ellos con argumentos tan banales como el que dichas acciones eran sino un "honor para la mujer", obviando algunos de los elementos que se plasmaban en las historias como la violencia, el poder y la sexualidad viril. En definitiva, aspectos que aportaban a las narraciones una fuerte carga sexista y misógina, perjudicial para su figura (Molas, 2006: 35). El más destacado, y el que refuerza la base del sistema patriarcal que se proyecta en los relatos, es el ejercicio de violencia aplicado sobre las mujeres. Por ello únicamente queda preguntarse qué se entiende por este tipo de violencia y qué aspectos incluye.

Si se recurre a la Ley Orgánica 1/2004 sobre Medidas de Protección Integral contra la Violencia de Género, se puede observar que hace referencia a cualquier tipo de agresión ejercida sobre las mujeres (Martínez, 2013: 25):

por el hecho mismo de serlo, por ser consideradas, por sus agresores, carentes de los derechos mínimos de libertad, respeto y capacidad de decisión». Así pues, no solo se remarcan las agresiones físicas o psicológicas, sino además aquellas que coacten la libertad femenina, o esta se vea amenazada de algún modo. También incluye molestias de carácter inaceptable o intimidaciones hacia la víctima, más allá de las «lesiones intencionadas e ilícitas del cuerpo, la salud o la libertad de una persona. 
En la actualidad la violencia femenina queda muy bien recogida en las leyes, pero lo cierto es que la violencia en sí es un concepto bastante universal que se encuentra yacente en la propia cultura de cada periodo histórico, y no es tarea exclusiva del varón cambiar este aspecto, salvo de todos, ya que es un tema que repercute al mundo entero por estar inmerso en la cultura del ser humano. A su vez, la violencia como tal no tiene su razón de ser en el carácter del hombre de forma natural, sino más bien en la aceptación de la dominación masculina en un momento dado de la historia, donde prevalecía una visión androcentrista por todo el territorio griego, que favorecía al mismo tiempo la condición del varón fuera cual fuera su situación. Cabe señalar que dicha dominación se basaba «en la justificación de la diferencia construida entre los sexos, [...] donde los hombres [...] [asumían] un papel social en el que se presenta[ba]n como "líderes" y figuras de autoridad y poder sobre las mujeres» (Alzard, 2013: 8). Este reconocimiento es precisamente el que les permitía actuar con libertad y ejercer la fuerza oportuna hacia el sexo inferior. Aunque no solo eso. También podía llegar a ser el responsable directo de la aparición de otros términos similares como el acoso sexual, entendido este como (Mujeres en Red y Ameco, 2017: 1):

Todo comportamiento sexual, verbal o físico, no deseado por la persona acosada, [...] aprovechándose de una situación de superioridad o compañerismo y que repercute en las condiciones del entorno haciéndolas hostiles, intimidatorias y humillantes.

En resumen, el acoso sexual no es más que otra expresión de las múltiples relaciones de poder que poseían los varones sobre las mujeres y, por consiguiente, otro símbolo más de violencia. A través de estas breves puntualizaciones se observa que la violencia, el acoso sexual, las relaciones de poder, el androcentrismo, el machismo, el sexismo, etc., son términos que de una forma $u$ otra aparecen relacionados con la dominación masculina y es que un elemento como este no solo hacía acto de presencia en la sociedad antigua repercutiendo en ella a gran escala, sino que también formaba parte del discurso mitológico. En este sentido (Alzard, 2013: 9):

La dominación masculina, simboliza por medio de las diosas y figuras mitológicas femeninas la idea de que los hombres intentan "transcender» la propia especie, mientras que las mujeres, vistas como seres profundamente estancados [...], tienden a «arrastrar» a los hombres.

De esta forma, para conseguir el triunfo de la dominación masculina y, por ende, la subordinación femenina, se servían de la violencia. Concretamente de aquella dirigida contra el sexo femenino. $Y$ es que ser violento era una capacidad inherente entre 
los héroes y los dioses (Pérez, 2011: 60). Su objetivo principal consistía en remarcar las relaciones diseñadas por el sistema patriarcal, es decir, aquellas que se fundamentaban en la jerarquización y la desigualdad, o lo que es lo mismo, en la dominación entre sexos. Así pues, se muestra que la violencia siempre ha tenido un papel esencial en la dominación masculina, y si se quiere hablar sobre el tema no se debería pasar por alto este término y sus distintas acepciones, pues una de ellas es de gran utilidad para estudiar la figura de Europa.

En general la violencia es un concepto bastante común que suele aparecer en la vida cotidiana de las personas. Cualquier situación o problema hallado, por muy pequeño que sea, puede transformarse fácilmente en conflicto y derivar en conflicto violento donde la violencia prima sobre todas las cosas. La mitología, al igual que ha hecho con otros aspectos de la sociedad antigua, recoge este elemento y lo utiliza frecuentemente en sus historias, de manera que se convierte en uno de los recursos básicos de esta materia, de modo que no es difícil imaginar la variedad de acepciones que aparecen sobre el tema en la mitología griega. Pero si se acota el estudio al tipo de violencia que ejerce el varón sobre el sexo femenino pueden encontrarse tres opciones posibles al respecto. Por un lado, la violencia simbólica o implícita; por otro, la física o explícita, y, finalmente, la sexual.

Respecto a esta última cabe señalar que es una de las más recurrentes y complejas de la mitología. Suele aparecer en casi todos los argumentos, aunque lo hace de distinta forma, ya que la violación de un cuerpo femenino no siempre ha sido motivo de horror, sufrimiento o dolor. La diferencia principal se puede encontrar «en las actitudes mentales que enmascaran, o no, el sometimiento del cuerpo del otro mediante la fuerza y el terror. En el caso de las mujeres, esas actitudes mentales varían dependiendo de los sistemas de opresión ejercidos sobre ellas» (Molas, 2006: 49). Generalmente, el grado de opresión en la sociedad solía ser bastante elevado, lo cual hacía que dicha violencia sexual no fuese vista como algo negativo sino como algo normal. La propia opresión que actuaba sobre ellas las hacía callar y obedecer, mientras que los hombres en ningún momento se llegaban a sentir culpables por lo que hacían. Es más, el sistema patriarcal plasmado en los mitos hacía que estos utilizasen a las mujeres como simple mercancía, es decir, como un bien mueble más, y nunca se paraban a pensar cómo podía sentirse la mujer o si esta quería hacer según qué cosas.

Una de las características más destacadas de la violencia sexual, era la relación que este concepto mantenía con la capacidad reproductiva. En dichos casos, las uniones sexuales que se generaban tras una acción violenta -como podía ser un rapto o un acosotenían como objeto final otorgar la paternidad al "violador», pues 
era una forma más de demostrar que el deseo sexual masculino había quedado satisfecho, y que la madre -después de ese encuentro- estaría siempre a su disposición sin oponer resistencia. En la mitología, el hecho de no compartir una relación marital no era ningún tipo de impedimento para el hombre. Este podía hacer sobre la mujer lo que le viniese en gana. De hecho, la unión mediante rapto era una forma más de expresar el «orden social» y también el poder y la autoridad que tenía su figura (Díez del Corral, 2005: 80). Al fin y al cabo, la violencia ejercida sobre ella marcaba la dominación masculina. ${ }^{1}$

Gracias a la clasificación anterior sobre la violencia, se ha podido profundizar en la violencia de carácter sexual que es aquella que interesa para abordar la figura de Europa. Por otra parte, esta clasificación ha servido además para indicar los diferentes tipos de violencia que se pueden desencadenar contra las «víctimas»-la mayoría de ellas mujeres. Sin embargo, no se ha dicho nada respecto a la postura que estas adoptan en cada ocasión, pues la actitud que toman todas ellas puede variar según la personalidad o la situación vivida. Es importante tener en cuenta que el papel de "víctima» va más allá de los rasgos de sumisión y obediencia hacia un ser considerado "superior». Muchas veces las actitudes que se muestran son rebeldes y directas; nada que ver con lo anterior. Por ello, se pueden observar dos vertientes bastante diferenciadas en estos casos. Por un lado, una faceta más activa y, por otro, una faceta más pasiva. En el caso de Europa predomina la pasiva, pues esta termina sometiéndose a los deseos de su raptor.

Realmente, la pasividad de la mujer suele aparecer en aquellos relatos donde se evidencian ciertos rasgos de violencia sexual, tal y como ocurre en los diferentes raptos mitológicos. En ellos, lo que más destaca es la actitud sumisa que asume el personaje femenino frente al sexo opuesto. $Y$ aunque en un principio puede darse cierta oposición o resistencia en su figura, esta finalmente acaba permitiendo el abuso, de modo que lo que empieza siendo una violación termina viéndose como una unión libre y consentida entre dos individuos. Así pues, la mayoría de las jóvenes -diosas, heroínas, ninfas, mortales, etc.- son "acosadas sexualmente, perseguidas y tomadas más o menos a la fuerza por un dios [sin ningún problema]» (Esteban, 2005: 67). A su vez, la pasividad que adopta en los raptos sirve nuevamente para reforzar uno de los conceptos básicos de la sociedad patriarcal -la dominación masculina-, ya que es uno de los casos en los que la mujer se doblega a la voluntad del varón y hace lo que este quiere, y sucumbe a todos sus deseos, especialmente aquellos de carácter sexual.

\footnotetext{
${ }^{1}$ Este aspecto se abordará en el siguiente apartado dedicado al estudio del rapto de Europa.
} 


\section{Ejemplificación de la violencia sexual en la mitología: el rapto de Europa}

Europa es uno de los personajes más versionados de la mitología griega. Su origen sigue prestando todavía cierta confusión en algunos aspectos debido a las múltiples versiones existentes sobre el linaje al que perteneció. Grandes autores clásicos como Apolodoro, Hesíodo u Homero han contribuido en gran medida a tal confusión con sus relatos sobre Europa, de modo que resulta prácticamente imposible determinar con exactitud cuáles fueron las verdaderas raíces de este personaje mitológico. La versión más célebre de todas apunta a que fue hija del rey fenicio Agénor y de su mujer Telefasa -también conocida esta última como Argíope, una de las hijas del río Nilo (Grimal, 2008: 189). Ello la convierte automáticamente en princesa fenicia y así lo recogen algunos de los relatos donde se describe su figura y el rapto que sufrió de joven. Esta versión, además de ser la más extendida entre los clásicos, es también la más estudiada por los mitólogos contemporáneos, según lo demuestran algunas de sus investigaciones más recientes. Aun así, no hay que olvidar que la complejidad real de dicho personaje reside en el número tan variopinto de progenitores con el que se la ha identificado en más de una ocasión. En algunos casos, "se dice que Europa fue hija de Agénor, rey de los fenicios, y de la ninfa Melia y que tuvo como hermanos a Cadmo y a Taso» (Conti, 2006: 645). Otros, en cambio, afirman que Europa fue hija de Fénix -hermano de esta en algunas narraciones- y nieta de Agénor. ${ }^{2}$

En términos generales, estas son las versiones que más trascendencia han tenido en el panorama mitológico y literario a lo largo de la historia, aunque no son las únicas. Existen otras dos donde aparece reflejado un personaje femenino con su mismo nombre. En una de ellas se afirma que el padre de Europa fue un gigante Ilamado Tityo que habitaba en Beocia, mientras que en la segunda la joven está considerada una de las oceánidas, es decir, una de las hijas de Océano y Tetis (Marsá, 2008: 37). No obstante, ninguna de estas dos está relacionada, ni tampoco tiene nada que ver, con el rapto que sufrió Europa durante su juventud. El único rasgo que comparten todas ellas es el nombre, de modo que no hay que confundir unas versiones de otras. Únicamente aquellas que deben interesar en este análisis son las tres primeras, ya que se recrea en todo momento el rapto mitológico protagonizado por Zeus. Algo bastante evidente por otra parte, teniendo en cuenta que el origen de este rapto queda ligado precisamente al linaje familiar que se nombra en dichas historias. Concretamente, es la cambiante figura del padre quien da la clave de ello; bien fuera Agénor o Fénix,

\footnotetext{
${ }^{2}$ Esta versión parte de Homero y aparece plasmada en el canto XIV de su llíada cuando menciona a una tal hija de Fénice que dio a luz a Minos y Radamantis -hijos habitualmente relacionados con el personaje de Europa.
} 
en ambos casos Europa resultaba ser descendiente directa de la doncella Ío -personaje de gran importancia en el rapto de Europa, pues muchos consideran que este suceso fue consecuencia inmediata del rapto que sufrió este otro personaje tiempo atrás.

Pero, ¿̇a qué es debida realmente esta multiplicidad de versiones y de personajes con el mismo nombre? Por lo general esta cuestión responde a las fuentes que utilizaron los autores clásicos en sus escritos. La mayoría de los dioses y los mitos que se narran suelen remitir a historias y personajes todavía más remotos y anteriores a estos. No hay más que observar que la propia religión cristiana se sirve de personajes y símbolos paganos, bastante anteriores a ella, para constituir una nueva religión. Así pues, se podría decir que la mitología como tal no surge exclusivamente gracias a la inventiva de sus autores, sino más bien responde a un factor anterior. Lo único que han hecho ha sido limitarse a plasmar el conocimiento y las historias que les han llegado de otras fuentes más antiguas, con lo que ha sido el propio paso del tiempo el que ha terminado distorsionando los relatos originales hasta el punto en el que, a día de hoy, se pueden encontrar fácilmente distintas narraciones donde aparecen personajes con un mismo nombre. En lo que respecta a la figura de Europa, esta podría haberse inspirado en la antigua diosa semítica Astarté de origen fenicio (López y San Nicolás, 1996: 451). Algo que concordaría, en parte, con la versión más extendida sobre el rapto, puesto que su padre fue el fundador y rey de la antigua Fenicia, mientras que ella misma era considerada princesa de ese lugar. Cierto es también que la figura de esta diosa solía mostrar rasgos afines a otros personajes de la mitología griega como Hera, Deméter, Afrodita, etc. Aun así, es Europa quien mejor refleja esta asimilación, ya que se han encontrado algunas representaciones artísticas en determinados templos dedicados a esta antigua diosa semítica, donde el personaje aparece subido a lomos de un toro blanco. Es más, se podría llegar a afirmar que el persistente carácter sexual que tanto se plasma en las distintas narraciones tiene su origen concretamente en estas representaciones antiguas, en las cuales se puede observar a una diosa medio desnuda a lomos de un toro, adquiriendo rasgos eróticos y mostrando una potente vitalidad sensual y sexual. Por este motivo, algunos autores como J. M. Blázquez afirman que «el mito de Europa [no] es [más que] una leyenda fenicia conectada originariamente con el culto de Astarté» (López y San Nicolás, 1996: 455).

A pesar de todo «los mitos, tal como los conocemos hoy, son la creación de grandes poetas» (Arnaud, 1993: 8). Poco importa que se inspirasen en leyendas populares o fuesen producto de su propia inventiva, el caso es que fueron los grandes escritores clásicos de la Antigüedad quienes, en un momento dado, les dieron cabida e hicieron posible que sobrevivieran hasta la actualidad. De esta forma 
es como ha prevalecido el rapto de Europa en los diferentes saberes de la sociedad y en la propia mentalidad de los individuos durante todo este tiempo, pues fueron muchos los autores que se encargaron de plasmar este conocido relato en sus escritos. Homero y Hesíodo fueron los primeros en dejar constancia de ello; más tarde, les siguieron otros como Ferecides, Píndaro, Herodoto, Apolonio de Rodas, Mosco de Siracusa, Apolodoro, Horacio, Ovidio, Diodoro Sículo, Virgilio, Julio Higino, Pausanias, etc. Todos dedican unas líneas a hablar de Europa, pero solo unos pocos profundizan realmente en la figura de este personaje y el rapto que protagonizó.

El poeta siciliano del siglo II a. C., Mosco de Siracusa, es quizá uno de los autores que mejor plasma la historia en el papel. No porque encuentra una manera original de relatar el rapto mediante la introducción de determinados elementos novedosos o porque se centra más que otros en los detalles, sino más bien porque es uno de los pocos que transmite la verdadera agonía vivida por Europa durante el rapto. Concretamente, el momento en el que empieza a hacerse visible esta situación es cuando el personaje empieza a ser consciente de la realidad. Entonces aparece un fragmento en el texto en el que la joven se lamenta de haber subido a lomos de aquel novillo que parecía tan dócil y bueno en un principio: «iAy, cuán desafortunada soy yo, que he abandonado la casa de mi padre y seguido a este toro, que hago extraño viaje y voy errante sola!» (García y Molinos, 1986: 300). Posteriormente, empieza a implorar ayuda al mismísimo Poseidón, aunque todo resulta en vano. Es más, cualquier aspecto que pudiese mostrar la verdadera cara de la violación que estaba a punto de sufrir Europa termina desvaneciéndose en el momento justo en que Zeus expresa sus sentimientos. Ante esta declaración de amor, no solo consigue engañar a la joven, sino también al propio lector, el cual termina viendo el acto como algo normal y para nada violento.

Algo similar relataría un siglo más tarde el gran poeta Horacio. Este, mediante el monólogo que profiere Europa a mitad del relato, pretende hacer llegar la debilidad del sexo femenino describiendo una figura al borde de la locura, que acusa a su propia torpeza de todo lo que le está sucediendo, y llega incluso hasta el punto de insultarse por su imperdonable falta: «iDespreciable Europa!, tu padre ausente te está urgiendo: ¿por qué tardas en morir?» (Horacio, 2007: 428). Exclamaciones como estas son realmente las que demuestran, una vez más, la importancia del sexo masculino sobre el femenino. En este caso, la opinión del padre resulta fundamental y el hecho de que una doncella virgen hubiese sido capturada, podía significar el fin de toda relación entre padre e hija y, por supuesto, la deshonra hacia su familia.

Otro aspecto bastante señalado en este pasaje es la violencia sexual que actúa sobre Europa. A diferencia de otros autores, 
Horacio es mucho más sutil y opta por no hacerla explícita, por lo que concluye el relato antes de que llegue a producirse la unión entre los individuos. Sin embargo, la violencia sexual puede mostrarse de otras formas distintas, como a través del enfado. Esta es la única manera que encuentra Europa de resistirse a su raptor. No hay que olvidar que su condición de mujer pasiva la limita bastante a la hora de oponerse a la figura dominante. Por tanto, el autor encuentra a través de la palabra, la forma de expresar su disconformidad, y lo hace de la siguiente manera: «si alguien, airada como estoy, me entrega ahora aquel novillo infame, lucharé por desgarrarlo con el hierro y por quebrar los cuernos del monstruo hace poco tan amado» (Horacio, 2007: 428). Cierto es también que esta, al igual que cualquier otra mujer "víctima pasiva», termina doblegándose a la voluntad del varón, y sucumbe así a todos sus deseos. De poco le sirve el enfado que muestra al inicio del relato. Siempre sucede algo que la hace cambiar de opinión. En este caso, la aparición de la diosa Venus la hace recapacitar, pues esta le dice que no debe lamentarse, sino que debe sentirse dichosa y agradecida porque quien la había raptado era nada más y nada menos que el dios supremo. Así pues, gracias a la intervención de Venus, se consigue mostrar nuevamente el poder masculino sobre el femenino, o lo que es lo mismo, el orden social establecido en la Antigua Grecia.

En realidad, son muchas las formas de expresar el rapto de Europa en los textos clásicos. Cada autor se sirve de una técnica distinta para mostrar, de la mejor manera posible, uno de los raptos más representativos de la mitología griega. Mientras Herodoto es el único que parte desde una corriente racionalista para explicar el rapto, los demás ofrecen una visión fantástica, característica y propia de la mitología. En primer lugar, autores como Mosco de Siracusa u Horacio se centran sobre todo en la imagen femenina y explican cómo se siente Europa una vez capturada por el dios Zeus. Otros como Hesíodo tratan de plasmar la autoridad del varón, con la finalidad de someter a la joven y conseguir así cualquier cosa de ella. Finalmente, autores como Ovidio, se inclinan más por mostrar la "visión amable del rapto», describiendo a un Zeus enamorado, tratando de justificar con ello la acción violenta sobre Europa.

Como ya se ha dicho anteriormente, son muchas las formas posibles de expresar un rapto en los escritos. Mientras unos solo son capaces de ver y transmitir la parte buena del rapto, otros se dedican a describir la parte negativa. Pero, ¿cuál es la concepción real de un rapto mitológico? ¿Qué aspectos lo definen como tal? ¿Puede verse como un aspecto tan perjudicial para la mujer si se analiza desde un sentido positivo?

En términos generales, el rapto mitológico «alude a la unión física de la pareja y [...] vendría a ser una especie de cliché que 
resumiría los diferentes pasos de la seducción» (Díez del Corral, 2005: 75). A través de esta breve definición se puede percibir de entrada una visión poco romántica de un aspecto que terminó convirtiéndose en uno de los temas más recurrentes de la mitología griega. En cualquier situación donde se relataba un rapto, la seducción y el deseo eran los factores que primaban y estaban presentes, en todo momento, en el panorama mitológico antiguo. En este sentido, el deseo propiamente dicho podía "sentirlo un humano hacia otro humano o una divinidad hacia un mortal, y [...] [podía] ser, a la vez, deseo hacia una persona del mismo sexo o del sexo contrario" (Zaragoza, 2006: 71). Estas eran las dos opciones más recurrentes de la mitología, pero no las únicas disponibles. Tanto los que sufrían el acoso en primera persona como aquellos que realizaban la acción no se limitaban a dioses o simples mortales. Realmente, la gama de personajes que protagonizaba un rapto era bastante extensa, de modo que también era posible encontrar entre los escritos a gigantes, centauros, sátiros, ninfas y un largo etcétera (Alamillo, 2002: 1). Por otro lado, mientras el rapto en sí se servía de unos mismos patrones a la hora de actuar, el desenlace que ofrecía variaba constantemente según el personaje que lo llevase a cabo. Cuando se trataba del deseo de una divinidad, el raptor siempre conseguía lo que se proponía, en este caso, el objeto anhelado. "Por el contrario, si se trata[ba] de un mortal [...] las quejas, las frustraciones y los deseos no consumados [...] [se convertían] en una constante» (Zaragoza, 2006: 71). Sin embargo uno de los aspectos que más llama la atención en todo esto, no es el poder que parecía tener la divinidad frente al mortal, sino más bien el sexo de cada uno de los protagonistas, especialmente aquel que llevaba a cabo el rapto. A diferencia de la víctima, el raptor pertenecía siempre al sexo masculino. Es más, sus frecuentes escarceos amorosos, así como su carácter enamoradizo y caprichoso, convertían a Zeus en uno de los mayores exponentes, tal y como se ha podido comprobar mediante el rapto que protagoniza junto a la joven Europa.

El dios supremo llegó a raptar numerosas figuras femeninas. Incluso en una ocasión, decidió hacer lo mismo con un joven llamado Ganimedes. Aun así, lo que verdaderamente llama la atención no son los individuos que raptó, ni tampoco el número de infidelidades que cometió hacia su mujer Hera, sino más bien las artimañas que solía utilizar para llevar a cabo su cometido. Al igual que en el caso de Europa -donde Zeus decidió adquirir forma de toro blanco para engatusar, engañar y raptar a la joven princesa que estaba tranquilamente cerca de la orilla recogiendo flores con sus amigas-, este era bastante propenso a metamorfosearse en cualquier cosa. De este modo, es fácil encontrar en algunos mitos como los de Alcmena, Leda, Ganimedes, Ío, Dánae o Antíope al «padre de los hombres y rey de los dioses» convertido en hombre, cisne, águila, nube, oro o 
sátiro, respectivamente (Conti, 2006: 95). Le daba igual ser un objeto, un animal o un ser humano si con ello conseguía su propósito. Por tanto, cabe preguntarse lo siguiente: «¿ंen qué figura no se metamorfoseó [...] para conseguir los amores deseados? ¿A qué cantidad violó con engaños? ¿Con cuántas innumerables cometió estupro?»(Conti, 2006: 106). Esto es algo que no se sabe con certeza, ya que son incontables las historias sobre raptos y transformaciones. Lo que sí se puede decir es que las metamorfosis no solo afectaron al raptor, sino también al personaje raptado (Zaragoza, 2006: 72). Sin ir más lejos, la tatarabuela de Europa -Íofue metamorfoseada por Zeus en ternero para protegerla así de la ira de su mujer Hera.

Pero independientemente de que las metamorfosis partiesen de unas $u$ otras figuras, el aspecto que más destaca de todos es el trasfondo violento que oculta el rapto mitológico. En realidad, no deja de ser una violación, o mejor dicho, el paso previo a una violación, así que poco importan los matices o el contexto idílico que se pueda reflejar en algunas de estas historias; el significado de dicho concepto va a seguir siendo el mismo. Así es como se puede observar una vez más la correspondencia del mito con la realidad. Hay que tener siempre presente que los mitos «no son solo ficciones, sino maneras de hacer más comprensible el orden del mundo" (Zaragoza, 2006: 63). De esta forma, el rapto podría interpretarse fácilmente como la violencia que ejercía sobre la mujer el sistema patriarcal implantado en el Mundo Antiguo. Un sistema en el que "women were viewed symbolically and literally as properties [...] and domination over them increased the male's prestige» (Pomeroy, 1975: 25).

Dicho esto cabe señalar que la dominación masculina primaba en todos estos relatos y era prácticamente un insulto replantearse la situación a la inversa, es decir, que fuera alguien del sexo femenino y no masculino quien dominase al otro, ya que existía una fuerte necesidad de probar la masculinidad y de revalidarla continuamente. Por esta razón, se considera que «ser hombre significa mantener el rol respecto a las mujeres; no serlo, ser dominado por estas, implica la pérdida de la condición de varón, la feminización simbólica, [...] la pérdida ante sí mismo y la sociedad [...] de la masculinidad» (Wulff, 1997: 63). A su vez, muchos autores parten de este concepto de dominación para comprender y estudiar los diferentes raptos de la mitología griega. Sin ir más lejos, la neerlandesa Eva Keuls (1993: 47) afirma que "rape is the ultimate translation of phallicism into action. Rape is committed not for pleasure or procreation, but in order to enact the principle of domination by means of sex». Estas palabras sustentan la idea esencial de la estructura patriarcal antigua, donde es «el hombre [quien] desempeña un papel de clara preponderancia, [...] ejecuta y sostiene ese sistema» (Díez del Corral, 2005: 76). Con 
ello se observa que el rapto en sí no solo puede reducirse a una cuestión de violencia; también puede interpretarse como una forma de dominación hacia el sexo femenino e incluso podría llegar simbolizar la condición de inferioridad social de la mujer griega, si se analiza desde la perspectiva del raptado y no del raptor.

Con todo esto es necesario volver a replantearse algunos de los pilares básicos de la sociedad griega; concretamente aquellos referidos a la relación entre hombres y mujeres. Si los mitos no eran más que un reflejo de la realidad, ¿quién es el culpable directo de esta condición: la propia cultura o la naturaleza en sí? Es la naturaleza la que separa, en primera instancia, hombres y mujeres, pero es la propia cultura quien ha interpretado y se ha encargado de difundir la inferioridad femenina. Sin embargo, las opiniones sobre el rapto mitológico distan bastante del análisis establecido anteriormente. Algunos consideran que es «biology and not culture is the source of rape» (Sorkin, 2011: 3). Quienes sustentan esta teoría aseguran que el rapto como tal responde a una cuestión natural y no a una construcción social, de modo que la dominación del poder fálico y la victimización femenina que se genera en este tipo de situaciones, parten desde una base plenamente natural y biológica (Zeitlin, 1986: 123). Ello se debe a que la sexualidad de los seres humanos es un factor más de la naturaleza, por lo tanto afirman que "the impulse to seize the female and take her against her will is an act profoundly linked to the conception of nature» (Zeitlin, 1986: 125), pues es el propio instinto quien les obliga a actuar. Es más, algunos autores reconocidos en la materia acusan al placer incontrolado, es decir, al natural, de cometer faltas y acciones vergonzosas, como aquella que llega a obligar a Zeus a metamorfosearse en animal para conseguir aquello deseado (Conti, 2006: 749). En contra, los hay que culpabilizan al hombre de haber creado una "rape culture», ya que las mujeres han sido entrenadas desde la Antigüedad para obedecer la voluntad del varón. Algo que recogería a la perfección la actitud pasiva que muestran tanto en el panorama social como en los mitos, sobre todo en aquellos donde el foco central es el rapto mitológico -en el que estas son forzadas y violadas por alguien del sexo masculino (Sorkin, 2011: 2).

Sea la naturaleza la culpable o lo sea la cultura, la mujer siempre se ha visto en desventaja con respecto al hombre. Esta siempre ha ocupado un segundo plano en la sociedad y ello ha terminado repercutiendo negativamente en los mitos. Los raptos mitológicos no son más que un ejemplo de una larga lista donde se percibe esa condición de inferioridad femenina. Aun así cabe señalar que no todos los mitólogos ofrecen una imagen tan catastrofista de los raptos como las ya comentadas. Algunos prefieren interpretar el rapto desde una corriente positiva. En este caso el rapto mitológico «deja de significar una clara agresión ejercida contra las mujeres 
para constituir un banal tema amoroso, una actividad de entretenimiento [...], un juego divertido entre amantes» (Huntingford, 2006: 129). En cambio, otros como Pilar Díez del Corral prefieren hablar de un fuerte paralelismo hallado entre el rapto y el matrimonio. En esta ocasión, la autora lo analiza también desde una perspectiva positiva, y afirma que el rapto responde a una tradición de origen espartano. En este sentido, la metáfora marital haría referencia a un "tipo de matrimonio que se denominaba así, matrimonio por rapto, especialmente en Esparta donde la ceremonia empezaba por [el] [...] (rapto) de la novia» (Alamillo, 2002: 2). También en esta segunda teoría se estaría representando la unión de los individuos y no la dominación de un sexo sobre el otro. Básicamente, llegan a esta conclusión tras observar determinados raptos de la mitología griega donde el rapto termina en matrimonio, de modo que lo que empieza siendo un "acto de violencia y sumisión» termina finalmente dando lugar a una vida conyugal como es el caso de Zeus y Hera, quienes gozaron de un matrimonio feliz durante más de trescientos años (Atsma, 2017).

Como se ha podido comprobar existe una gran correlación entre los mitos y la sociedad en la que estos convivieron. Según los diferentes mitólogos, la sociedad antigua influye considerablemente tanto en la visión como en el significado real que ofrece el rapto en la mitología griega. Este es un aspecto que ha servido, de un modo u otro, no solo para entender algunos los rasgos de la Antigua Grecia, sino también para estudiar otros conceptos actuales que guardan cierta relación con el rapto mitológico. Es cierto que la sociedad ha evolucionado en este sentido y ya no se sigue mostrando una imagen femenina débil, sumisa y obediente como la que se transmite en los raptos o la que persistía en la sociedad patriarcal griega. No obstante, otros aspectos como la trata de mujeres siguen presentando algunos de sus rasgos más característicos.

\section{Discusión y conclusiones}

Con este proyecto de investigación se ha tratado de fomentar el estudio sobre la violencia de género hallada en la mitología griega, con la finalidad de comprender un poco más la sociedad en la que tuvo una gran importancia. Es vital tener siempre presente que la mitología en sí responde, en gran parte, al pensamiento de los individuos griegos, ya que fueron ellos los encargados de su creación y los que terminaron reflejando en sus historias ciertos aspectos del Mundo Antiguo, mientras los propios mitos ayudaban a perpetuar, legitimar e incluso naturalizar el pensamiento de la sociedad gracias a los múltiples mensajes -ocultos y no tan ocultos- que ofrecían, donde quedaba desprestigiada continuamente la figura femenina. 
Es evidente que el análisis que se profiere sobre el «rapto de Europa» es un tema que puede abordarse desde distintas vertientes gracias a su amplitud en contenido. Las corrientes artística o literaria son dos de las más recurrentes en este sentido, incluso se utilizan algunas veces juntas para ofrecer un estudio más completo. No obstante, en esta ocasión la categoría de género ha constituido el eje vertebrador de este trabajo y es, además, el que ha permitido estudiar el personaje de Europa. Gracias a esta categoría, la investigación ha podido tomar, en primer lugar, una línea más teórica que ha servido para ofrecer posteriormente otra más práctica que ha llevado al análisis de una figura concreta, en este caso Europa y el rapto que protagonizó durante su juventud. Asimismo, se ha demostrado que un elemento tan simple como los mitos, a simple vista, puede ofrecer información bastante valiosa respecto al contexto en el que se crearon y extraer, a su vez, reflexiones interesantes que puedan acercar cada vez más al individuo a la mentalidad de la sociedad griega. Por este motivo, resulta imprescindible promover su estudio. No hay que menospreciarlos, sino todo lo contrario, pues no dejan de ser una gran herramienta para poder llegar a reconstruir, a grandes rasgos, la historia del pasado.

\section{Bibliografía}

Alamillo, Assela. 2002. "El rapto en la mitología clásica», conferencia dictada durante el X Seminario de Arqueología Clásica. Madrid: Universidad Complutense de Madrid, el día 30 de octubre de 2002. Acceso del 30 de noviembre de 2017 http://pendientedemigracion.ucm.es/centros/cont/descargas/d ocumento12005.pdf.

Alzard, Dunia. 2013. Construcciones y estereotipos de feminidad reforzados a partir de la mitología clásica: el caso de Afrodita, Hera y Atenea, Trabajo Final de Máster. Madrid: Instituto de Investigaciones Feministas, Universidad Complutense de Madrid.

Arnaud, Margot. 1993. La mitología clásica. Madrid: Acento.

Atsma, Aaron J. 2017. "Hera Myths». En Theoi Greek Mythology, http://www.theoi.com/Olympios/HeraMyths.html\#Seduction. Acceso del 13 de diciembre de 2017.

Conti, Natale. 2006 Mitología. Murcia: Universidad de Murcia.

Díez del Corral, Pilar. 2005. «El rapto: ¿una forma de amor? Una interpretación de las imágenes de persecución y rapto de Dioniso y Ariadna». Gallaecia 24: 75-97. 
Esteban Santos, Alicia. 2005. "Mujeres terribles (Heroínas de la mitología griega)». Cuadernos de la filología clásica: Estudios griegos e indoeuropeos 15: 63-93.

García, Manuel y María Teresa Molinos. 1986. Bucólicos griegos. Madrid: Gredos.

Grimal, Pierre. 2008. Diccionari de mitologia grega $i$ romana. Barcelona: Edicions de 1984.

Horacio. 2007. Odas, Canto secular, Epodos. José Luis Moralejo, ed. Madrid: Gredos.

Huntingford, Elisabet. 2006. "VI. Persecución, desesperanza y muerte femeninas en las imágenes griegas». En La violencia de género en la antigüedad, editado por Maria Dolors Molas, 125168. Madrid: Instituto de la Mujer.

Keuls, Eva C. 1993. The Reign of the Phallus. Sexual politics in Ancient Athens. Berkeley: University of California Press.

López, Guadalupe y María Pilar San Nicolás. 1996. «Astarté-Europa en la Península Ibérica: un ejemplo de interpretatio romana». Complutum 6: 451-470.

Marsá, Verónica. 2008. «El origen de Europa ¿Mítico o geográfico?». En Europa: historia, imagen y mito. Europa: Geschichte, Bilder und Mythos, dirigido por José J. Ferrer Maestro y Pedro Barceló, 37-46. Castelló de la Plana: Publicaciones de la Universitat Jaume I.

Martínez, Elena. 2013. "La experiencia española en la prevención y erradicación de los delitos de violencia de género: perspectivas de futuro en un marco comparativo europeo». Asparkía: Investigación feminista 24: 19-34.

Molas, Maria Dolors. 2006. «Il. Las violencias contra las mujeres en la poesía griega: de Homero a Eurípides». En La violencia de género en la antigüedad, editado por Maria Dolors Molas, 33-62. Madrid: Instituto de la Mujer.

Mujeres en Red y Ameco. 2007. «Vocabulario para la igualdad. Palabras y conceptos clave en el vocabulario de la igualdad». Construcción colaborativa permanente, 1-10. Acceso del 2 de diciembre de 2017 http://www.mujeresenred.net/spip.php?article1301.

Pérez Miranda, Iván. 2011. Mito y género en la Grecia Antigua. Tantálidas, Labdácidas y Dardánidas, Tesis doctoral. Departamento de Prehistoria, Historia Antigua y Arqueología, Universidad de Salamanca. 
Pomeroy, Sarah B. 1975. Goddesses, Whores, Wives and Slaves: Women in Classical Antiquity. Nueva York: Schocken Books.

Ruiz Gómez, Norma Liliana. 2004. "La mitología griega en la identidad de género». Revista Tepes 2: 1-29.

Sorkin, Nancy. 2011. «Greek Tragedy: A Rape Culture?». Eugesta 1: $1-21$.

Wulff, Fernando. 1997. La fortaleza asediada. Diosas, héroes y mujeres poderosas en el mito griego. Salamanca: Universidad de Salamanca.

Zaragoza, Joana. 2006. «III. Violencia y misoginia: los raptos». En Maria Dolors Molas y otros. La violencia de género en la antigüedad, 63-76. Madrid: Instituto de la Mujer.

Zeitlin, Froma. 1986. "Configurations of Rape in Greek Myth». En Rape, editado por Tomaselli Sylvana y Roy Porter, 122-151. Oxford y Nueva York: Basil Blackwell. 